\title{
Revisitando os Fundamentos da Educação para a Libertação: o legado de Paulo Freire
}

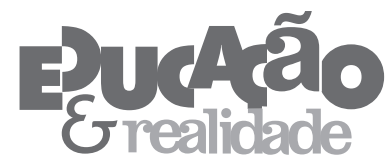

\author{
Ronald David Glass' \\ 'University of California, Santa Cruz (UCSC), Santa Cruz/CA - Estados Unidos
}

RESUMO - Revisitando os Fundamentos da Educação para a Libertação: o legado de Paulo Freire. Este artigo examina, critica e amplia os fundamentos ontológicos, epistemológicos, éticos e políticos da teoria da educação libertadora de Paulo Freire; também situa o legado de Freire dentro da aplicação global de suas ideias em um amplo espectro de contextos educacionais. O texto defende historicidade e práxis como características essenciais da natureza humana, expõe os problemas das noções de identidades autênticas e constrói um entendimento historicizado da produção de conhecimento. $\mathrm{O}$ artigo defende que a educação libertadora deve estar baseada em uma ética sem presunção acoplada a uma política de não-violência militante.

Palavras-chave: Freire. Educação Libertadora. Ética. Ontologia. Epistemologia. Filosofia da Educação.

ABSTRACT - Revisiting the Foundations of Liberation Education: Paulo Freire's legacy. This essay examines, critiques, and extends the ontological, epistemological, ethical, and political foundations of Paulo Freire's theory of liberation education; it also situates Freire's legacy within the global application of his ideas in a wide range of educational contexts. It defends historicity and praxis as essential characteristics of human existence, exposes the problems with notions of authentic identities, and elaborates a historicized understanding of knowledge production. The essay argues for liberation education to be grounded in an ethics without righteousness coupled with a politics of militant nonviolence.

Keywords: Freire. Liberation Education. Ethics. Ontology. Epistemology. Philosophy of Education. 
Revisitando os Fundamentos da Educação para a Libertação

\section{Introdução}

A última vez em que revisei a filosofia da práxis de Paulo Freire e os fundamentos da educação para a libertação foi em um ensaio publicado em Educational Researcher em 2001 e, embora eu ainda sustente os argumentos que desenvolvi na época, diversas lacunas e obscuridades ainda merecem ser examinadas ${ }^{1}$. Neste ensaio revisito alguns destes aspectos e faço uma nova reflexão sobre o legado de Freire, embora naturalmente muito ainda continue fora do escopo do que ofereço aqui.

Pessoas do mundo todo continuam a lamentar a morte de Freire, assim como continuam a se inspirar com seu trabalho e trazer a visão dele à vida em seus projetos. A conceituação imperfeita de educação de Freire como uma prática de liberdade não impede a reinvenção de suas ideias em uma ampla variedade de contextos. A boa teoria busca clareza e consistência, mas também, necessariamente, persegue verdades que são sempre vividas em obscuridades e contradições. A inescapável opacidade da existência humana admite apenas breves lampejos da nossa própria realidade e de nossas situações, mas estes vislumbres de insights e compreensão deixam traços suficientes a serem procurados, permitindo que nossa linguagem aponte para o que enxergamos e propicie que nosso discernimento fique mais visível em nossas teorias ${ }^{2}$. Paulo Freire viu e sentiu profundas verdades a respeito dos seres humanos, e um número incontável de pessoas continua grato por ele ter tentado tão corajosamente captar nossa realidade humana e expressá-la; seu esforço determinado rendeu uma frutífera teoria agora legada à história, independente de suas limitações.

Neste ensaio, também persigo verdades e tento dizer com um pouco de clareza o que tenho visto apenas difusamente. Reafirmo o legado de Freire na densidade da vida e defendo algumas das afirmativas ontológicas centrais de Freire em relação a posições epistemológicas, éticas e políticas não fundacionistas. No decorrer do texto, amplio algumas das críticas e argumentos que ficaram necessariamente truncados por limitação de espaço no meu ensaio de 2001 e trago uma parte do que venho aprendendo ao longo dos anos com outros pensadores, ativistas e meus estudantes.

\section{O Crescente Legado de Freire}

A voz de Freire de fato sobreviveu ao seu falecimento físico porque vários livros com seus escritos foram publicados postumamente (Freire, 1997; 1998a; 1998b; 2004). Estas coletâneas de ensaios abrangiam muitos tópicos, desde reflexões altamente abstratas sobre modelos teóricos chave até aplicações centradas em professores de sala de aula, e também situavam aspectos de seu desenvolvimento intelectual e político dentro do escopo de sua autobiografia. Alguns dos ensaios debatiam assuntos emergentes em torno de tecnologia, e outros contestavam a lógica e as instituições neoliberais e sua violenta ingerência não apenas

832 Educação \& Realidade, Porto Alegre, v. 38, n. 3, p. 831-851, jul./set. 2013 Disponível em: <http://www.ufrgs.br/edu_realidade> 
nas escolas, mas também na vida cotidiana. No final de seus dias como escritor, a leitura e a escrita de Freire sobre a realidade fluíam de seu compromisso ético e político, o que continuou firme ao lado dos pobres e dos mais desfavorecidos. A indignação de Freire contra a opressão e a desigualdade alimentava suas denúncias e determinação em fazer com que sua teorização servisse à liberdade, à justiça e à democracia. De forma semelhante, seu profundo amor pelos outros inspirou sua sensibilidade à dimensão ética da luta por justiça e tornou sua presença e ensino magnéticos e inspiradores para outros (Freire, 2001). Ninguém pode duvidar de que sua vida como intelectual orgânico e comprometido assegure a durabilidade de seu legado, mesmo que suas formulações teóricas continuem contestadas (Fischman; McLaren, 2005).

No entanto, vários estudiosos observaram que muitos elementos do pensamento de Freire não eram originais seus, mesmo quando sua habilidade em sintetizar ideias e articulá-las de acordo com a sua própria prática educacional democrática e emancipatória tenha levado ativistas e estudiosos a se apropriarem de partes de sua teoria para seus próprios fins no mundo todo. Alguns estudiosos interrogaram a teoria de Freire em relação a sua formação integral dentro das forças e projetos políticos que ocupavam seus dias (Schugurensky, 2011) ou nas particularidades de sua história de vida (Kirylo, 2011), e outros argumentaram que as lutas econômicas e políticas globais, ou mesmo as dinâmicas de super poder, foram mais reveladoras para compreender o formato e a força do pensamento e da prática de Freire (Fischman et al, 2005; Kirkendall, 2010; Torres, 2009). Porém, apesar de ter-se optado por interpretar os fatores antecedentes que condicionaram a prática e as ideias de Freire, poucos contestariam o óbvio fato de que o chamado para que os educadores desempenhem uma pedagogia crítica para propiciar uma alfabetização emancipatória entre os educandos teve um impacto que encantou a professores do mundo inteiro (McLaren; Kinchloe, 2007).

Em um contexto global de políticas neoliberais que produzem escolas orientadas por regimes de testagem, classificação e seleção que lembram uma quase paródia do famoso modelo bancário de educação de Freire (Freire, 1994a, capítulo 2), os professores são reduzidos a sistemas robotizados de fornecimento de currículo lendo instruções de um roteiro para estudantes que são, eles mesmos, reduzidos a máquinas que repetem a orientação recebida. Assim, não é surpresa que o legado de Freire encontre um papel vital em manter viva uma visão diferente, de uma alfabetização humanizadora que engaje os estudantes em projetos de justiça social e reflexões críticas sobre suas próprias vidas (Giroux, 2011; Roberts, 2000; Slater; Fain; Rossatto, 2002). A incorporação das experiências e vozes em discussões de sala de aula e temas de casa por escrito talvez marque a forma mais disseminada da influência de Freire em práticas de escolarização no ensino fundamental (Perry, 2000; Souto-Manning, 2010). Esta ênfase na sala de aula alinha-se a uma integração mais ampla dos aspectos comunicativos ou baseados na lin-

Educação \& Realidade, Porto Alegre, v. 38, n. 3, p. 831-851, jul./set. 2013.

Disponível em: <http://www.ufrgs.br/edu_realidade> 
Revisitando os Fundamentos da Educação para a Libertação

guagem da problematização e pedagogia centrada no aluno de Freire em um rol diversificado de contextos educativos em todos os níveis quando os professores procuram criar ambientes de aprendizagem humanizadores (Richards; Thomas; Nain, 2001; Walcott, 2006). Os múltiplos sítios que foram transformados por influência das ideias de Freire também compartilham seu compromisso com um profundo respeito, até mesmo amor, pelos educandos (Darder, 2002) e, por meio desta relação de mutualidade, espera-se que os aprendizes descubram seu poder de intencionalmente transformarem a si e ao seu mundo (Rossatto, 2005), talvez até mesmo ajudando a evitar a catástrofe ambiental global que se desenrola na esteira da globalização (Bowers; Appfel-Marglin, 2005). Este otimismo para com as possibilidades de programas educacionais, localizados em escolas e outras instituições da vida cotidiana, permeia o movimento da pedagogia crítica e o tem feito desde seu começo, mas as possibilidades de agir por uma mudança significativa nas estruturas de opressão nestes contextos devem ser questionadas (Apple, 2013). Ali reside o perigo da domesticação da teoria de Freire quando está confinada a processos curriculares em escolas, particularmente quando estas não estão vinculadas a intervenções críticas nas dinâmicas de opressão.

Embora as limitações das estruturas institucionais existentes geralmente impeçam uma implementação profunda das ideias de Freire, elas coexistem com aberturas que merecem ser ampliadas e exploradas em busca de finalidades progressistas. Não apenas estes esforços podem sustentar o impulso democrático da escolarização pública, mas também o emprego das ideias de Freire em instituições e contextos alternativos já engajados em lutas emancipatórias pode aproximar-se da realização da promessa de uma pedagogia emancipatória (Mayo, 1999; 2004). De fato, alguns defenderam que somente uma abordagem freireana à educação como uma prática de liberdade consegue responder adequadamente às transformações na natureza da opressão no atual período pós-moderno (O’Shea; O’Brien, 2011). Daniel Schugurensky (2011) defendeu que as contribuições mais duradouras de Freire estenderam as concepções progressistas de educação para além do liberalismo e sua frequente fé ingênua em educação pública, para acolher o poder transformador de colocar a práxis no âmago da aprendizagem e da existência humana.

A força liberada por este entendimento explica porque, tanto estudiosos quanto ativistas, continuaram comprometidos em empregar o trabalho de Freire - para conter a crescente expansão de políticas neoliberais e neoconservadoras - e a reconcentrar esforços - para fazer com que a educação pública e outras instituições sociais sirvam a finalidades emancipatórias e democráticas. O impacto desta força levou pelo menos um estudioso proeminente a comparar Freire com o legendário revolucionário Che Guevara e a defender que a teoria de Freire poderia transformar a vida cotidiana em uma escala histórica mundial (McLaren, 2000). Esta não é uma comparação inútil, mas sim a significância

834 Educação \& Realidade, Porto Alegre, v. 38, n. 3, p. 831-851, jul./set. 2013 Disponível em: <http://www.ufrgs.br/edu_realidade> 
da amplitude e da profundidade do legado de Freire e sua capacidade duradoura de moldar o pensamento e a ação de todos aqueles que sonham com um mundo democrático justo.

\section{Os Argumentos de Freire Revisitados}

Embora o legado de Freire ao rol de estudiosos, ativistas e professores comprometidos continue a crescer e enriquecer as lutas por um futuro mais humano, muitas dimensões de sua teoria em si continuam problemáticas. Nesta seção do ensaio, resumirei muito brevemente alguns dos argumentos ontológicos, epistemológicos e ético-políticos centrais na teoria de Freire, conforme foi inicialmente articulada em Pedagogia do Oprimido, sendo depois modificada um pouco nos últimos anos em resposta a críticas e a desdobramentos de seu próprio pensamento. Conforme argumentei (2001, p. 16), uma teoria adequada da educação como prática de liberdade deve enunciar em mais detalhes do que Freire fez sobre como "[...] um tipo de psicanálise históricocultural política" (Freire, 1994b, p. 55) pode resultar em um "[...] pósmodernismo progressista" (Freire, 1994b, p. 10), ética e politicamente, mais defensável. A força da crítica modernista de Freire a respeito da desumanização e da opressão deve ser integrada a uma compreensão mais crítica da identidade como maleável, dinâmica e contraditória, tanto em nível de indivíduo como de grupos, sendo classes, raças ou gêneros. Além disso, uma teoria adequada deve acolher mais profundamente uma consciência incorporada, reconhecendo não somente como isso perturba as noções de razão e epistemologia de Freire, mas também como demanda transformações na compreensão dele da explicitação pedagógica de consciência crítica. Finalmente, uma pedagogia emancipatória, incorporada em lutas por justiça e democracia, deve estar alicerçada em uma ética e uma política consistentes com estas posições ontológicas e epistemológicas; e consistentes com diferentes estruturas éticas e concepções do bem que sejam convincentes e diversificadas (Glass, 2011).

A teoria de educação como prática de liberdade de Freire repousa sobre uma afirmativa ontológica de que o aspecto definidor da existência humana é que produzimos história e cultura ao mesmo tempo em que história e cultura nos produzem: "[...] a historicidade das pessoas" é o "[...] ponto de partida" (Freire, 1994a, p. 65). Por meio do nosso trabalho, por meio de nossa atividade em nossas vidas cotidianas, produzimos nossa subsistência e também os sentidos de que são imbuídos nossas atividades. $\mathrm{O}$ ambiente concreto de nossos corpos materiais e o mundo natural circundante condicionam nossa produtividade; similarmente, a história e a cultura da comunidade, na qual fomos jogados e na qual chegamos à consciência, condicionam os sentidos com os quais compreendemos nosso mundo e a nós mesmos. Nossa historicidade marca o espaço de nossa liberdade, a maneira pela qual transcendemos continuamente a situação presente. Em nossa capacidade de transfor- 
Revisitando os Fundamentos da Educação para a Libertação

mar o mundo material, os sentidos e as práticas histórico-culturais que recebemos ou foram repassados a nós, representamos nossa liberdade e fazemos algo novo ou diferente a respeito de nossa situação.

Concordo com Freire em que a historicidade humana e a práxis resultante oferecem uma posição ontológica embasadora de nossa liberdade para uma pedagogia crítica. Existem dois corolários chave. Primeiramente, Freire define a opressão como desumanização, e a desumanização como as estruturas e processos que inibem ou impedem uma realização consciente de nossa liberdade (nossa historicidade e nossa capacidade para uma práxis crítica); assim, a reivindicação destas capacidades humanas fundamentais se torna emancipatória, além de uma maneira de superar os limites impostos. E, obviamente, a desumanização e a opressão devem ser impostas, já que são entraves à força mais vital e definidora da existência humana. Em segundo lugar, para romper estes limites é necessário uma pedagogia ou processo de aprendizagem que consiga nos despertar para uma força que já possuímos (nossa liberdade, nossa capacidade de transformar o mundo e a nós mesmos ao mesmo tempo em que história e cultura nos condicionam), aproveitando este poder para intervenções conscientes dirigidas aos limites estruturais em situações opressoras.

Este breve resumo captura a estrutura teórica mais básica e defensável de Freire, sendo forte o suficiente para apoiar as elaborações epistemológicas, éticas e políticas necessárias para orientar uma prática libertadora mais robusta. Esta estrutura ontológica não é afetada pela rejeição de diversas posições relacionadas de Freire que não podem ser sustentadas frente a contestações. Por exemplo, o argumento de Freire de que os humanos são singulares entre os animais ao produzirem cultura e história, ao trabalharem para transformar o mundo, não precisa ser defendido contra ataques de especismo ou invasão cultural (ver Bowers, 1983). A estrutura básica da teoria pode ser agnóstica nos debates sobre comparações interculturais ou sobre a consciência em outros animais. Tampouco devemos defender a insistência de Freire de que somente a humanização é uma vocação ontológica - os pressupostos teleológicos no conceito de vocação podem ser deixados para a teologia. A estrutura teórica básica aqui delineada pode tolerar a amarga verdade de que alguns humanos procuram fazer sua história e cultura, em parte, pela destruição desta possibilidade para outros; ou seja, a desumanização, de fato, é uma maneira de ser humano para algumas pessoas, porém isto não é uma ameaça ao posicionamento ontológico básico a respeito de historicidade e práxis, mesmo que certamente seja uma ameaça verdadeira a determinados seres humanos reais.

De forma semelhante, a estrutura básica não é afetada pela rejeição da confiança de Freire sobre uma posição de sujeito autêntico que está um pouco relacionada a sua noção de vocação. Afirmativas de um eu autêntico não podem ser sustentadas contra críticas da esperança iluminista feitas por ontologias fundacionistas (Adorno, 1973; Mar-

836 Educação \& Realidade, Porto Alegre, v. 38, n. 3, p. 831-851, jul./set. 2013. Disponível em: <http://www.ufrgs.br/edu_realidade> 
gonis, 1993). E, embora Freire reconhecesse os perigos de narrativas universalísticas incorporadas em seu entendimento de humanização (McLaren; Leonard, 1994), traços deste anseio nunca abandonaram sua perspectiva (Bhattarcharya, 2011), talvez devido à maneira como sua fé cristã animava sua vida (Freire, 1997/2004). Porém, sua posição ontológica repetida e mais consistente estava centrada na perpétua incompletude da existência humana; esta inescapável infinitude não apenas ilustra nosso modo ontológico de estar no mundo, mas ilumina a incerteza epistêmica que é, igualmente, uma condição de nosso saber e de nosso ser (Freire, 1994a; 1997/2004; 1998a).

Assim como Freire, ao longo de seus dias como escritor, continuou a refinar a posição ontológica que articulou em Pedagogia do Oprimido, também continuou a enfrentar as tensões em sua posição epistemológica. O desafio epistêmico mais urgente emerge da ontologia historicizada, que constitui a estrutura teórica básica para a educação como prática de liberdade e concerne à natureza do conhecimento e da verdade em si. Não apenas uma epistemologia não fundacionista precisa não apenas reconhecer as incertezas e limites inerentes em afirmativas de saber, mas também deve justificar suficientemente as afirmativas para que as condições de vida desumanizadoras e injustas possam ser nomeadas e contestadas. Isto é mais problemático quando o senso comum - os modos cotidianos comuns de saber sobre o mundo e o eu - estiver ideologicamente contaminado. Em níveis ainda mais profundos estão as complexas dificuldades que emergem quando pessoas oprimidas - seja como indivíduo, seja como classe - tentam discernir não só a verdade de suas identidades e suas situações, mas também tentam adquirir uma compreensão que alcance o lado oculto de como as coisas são (ou parecem ser) para captar o modo como aquelas aparentes verdades vieram a ser encaradas como autoevidentes. Este é o desafio de revelar o por quê e o como de nossas realidades econômicas, sociais, culturais e políticas, de construir o bom senso crítico onde prevalece o senso comum (ver Gramsci, 1971; Mayo, 1999).

Ao longo dos anos, Freire aproximou mais sua postura epistemológica de uma ontologia historicizada. Reconheceu que nossa existência ontológica, como coprodutores dos mundos históricos e culturais onde vivemos (e que formatam nosso saber e nosso modo de ser), está fundamentalmente conectada com nossa compreensão epistemológica daquelas mesmas realidades que nos incorporam (independente de quão inconscientes possamos ser disso) e que incorporam através de nossas ações. "Consciente de que posso conhecer social e historicamente, sei também que o que sei não poderia escapar à continuidade histórica. O saber tem historicidade. Nunca é, está sempre sendo" (Frei-

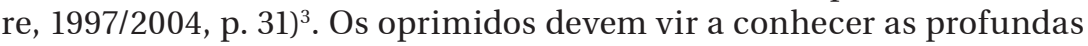
incertezas inerentes ao saber, sem que isso leve a um ceticismo debilitante. Freire insistia que os oprimidos tinham que despertar não só para suas possibilidades de ser, mas também para suas possibilidades de conhecer, e ambos os despertares forneciam o foco de uma pedago-

Educação \& Realidade, Porto Alegre, v. 38, n. 3, p. 831-851, jul./set. 2013.

Disponível em: <http://www.ufrgs.br/edu_realidade> 
Revisitando os Fundamentos da Educação para a Libertação

gia crítica. Ao ativar a curiosidade que orienta a busca por saber melhor o que já se sabe, saber o que ainda não se sabe sobre determinadas coisas e saber que se pode até mesmo "[...] produzir conhecimento ainda não existente" (Freire, 1997/2004, p. 31) ${ }^{4}$, as pessoas oprimidas conseguem estabelecer o embasamento epistêmico sobre o qual conduzir suas lutas emancipatórias.

Para Freire, este embasamento foi alcançado por intermédio de um foco no aprender, não em conseguir respostas, mas enfrentar com perguntas, para que o que for conhecido sistemática e deliberadamente além do que já era conhecido apenas experiencialmente e acriticamente, ou além do que era completamente desconhecido antes seja novamente, por sua vez, questionado. Freire argumentou que "[...] saber com mais rigorosidade metódica aumentaria o nível de exatidão do achado" (Freire, $1997 / 2004$, p. 31$)^{5}$, o que certamente é importante, e reconhecia o poder de colocar as disciplinas de pesquisa universitária a serviço dos menos favorecidos. Parecia incontestável para Freire que um "[...] corpo coerente, lógico, rigoroso” (Freire; Faundez, 1992, p. 39) ${ }^{6}$, que justifica o conhecimento crítico e orienta a ação emancipatória, deve utilizar formas científicas de questionamento e as verdades resultantes, bem como fazer uso da força da lógica filosófica e científica para compreender e modificar a realidade. Mas, ao mesmo tempo, estes discursos dominantes não podem ser a primeira nem a última palavra. Freire argumentava consistentemente contra um basismo unilateral que privilegiasse o senso comum das massas - o conhecimento da experiência cotidiana - da mesma forma como argumentava contra um elitismo unilateral que privilegiasse o senso treinado de intelectuais - o conhecimento das ciências sistemáticas - porque nenhum deles poderia oferecer uma garantia verdadeira (Freire, 1994b, p. 84-85; Freire; Faundez, 1992, p. 47-48).

Embora Freire nunca tenha se desviado de sua tentativa de evidenciar a unidade dialética do sujeito conhecedor, do objeto cognoscível e as necessárias contribuições de diversas maneiras de conhecer, com frequência ele também escorregou para uma linguagem epistemológica que enfatizava a compreensão de aspectos cognitivos. Este foi particularmente o caso na Pedagogia do Oprimido e outros escritos anteriores. No entanto, no final de seus dias como escritor, ele claramente queria dar a significância devida aos aspectos corporais e relacionais do saber que repousam sobre e em torno das dimensões cognitivas. Descentralizou sua linguagem racionalista e cognitivista anterior para oferecer uma visão sintética de consciência:

A consciência do mundo que implica a consciência de mim no mundo, com ele e com os outros, que implica também a nossa capacidade de perceber o mundo, de compreendê-lo, não se reduz a uma experiência racionalista. É como uma totalidade - razão, sentimentos, emoções, desejos - que meu corpo consciente do mundo e de mim capta o mundo a que se intenciona (Freire, 1995, p. 75-76) . 
Utilizando-se da fenomenologia de M. Merleau-Ponty $(1962)^{8}$, Freire aqui produz uma visão de consciência mais justificada do que aparece em muitas de suas discussões sobre epistemologia. Mais tarde, essa virada rumo a uma síntese fenomenológica mais explícita de sujeito/objeto e mente/corpo continua fundamentalmente sugerida, ainda deixando muitas lacunas na teoria de Freire. A formação discursiva de conhecimento e as maneiras como o poder permeiam estes processos historicamente construídos (Foucault, 1972; 1973) é mencionada majoritariamente de passagem em discussões epistemológicas de Freire. E seus enunciados gerais, como o acima citado, avançam apenas uma distância limitada, rumo à abordagem das profundas preocupações corretamente levantadas por feministas a respeito de ênfases excessivamente racionalistas e cognitivistas de Freire (Luke; Gore, 1992).

O conhecimento crítico desconstrói a historicidade de ser e saber, revela os limites e possibilidades em cada situação, desnaturaliza ideologias dominantes que invadem a experiência e ilumina as dinâmicas formativas constituintes do eu. Este conhecimento emerge dos profundos lugares do ser e, à primeira vista, é incipiente em nossos corpos, apresentando-se como intuição, como sentimentos aguardando por expressão. Este despertar corporal pode ser alcançado em encontros com o perigo, como quando uma mulher em um relacionamento com um parceiro abusivo, intuitivamente, sente a imanência de uma erupção violenta ${ }^{9}$, e muitas vezes é prontamente obtido em encontros emocionais com arte, poesia, música e outras formas simbólicas (Boler, 1999; Greene, 1986, 1988; Lewis, 2012). Freire também via que os códigos e a codificação simbólica da vida cotidiana, poderiam ser ferramentas poderosas para fazer com que o universo temático dos oprimidos se destacasse do cenário de senso comum que escondia a verdade sobre a situação deles, particularmente quando as codificações estão vinculadas a uma pedagogia descodificadora de questionamento crítico (ver Brown, 1978; Freire, 1994a, capítulo 3). Porém, ele não teorizava como o corpo em si, perante qualquer compreensão reflexiva cognitiva; não apenas motivava a análise crítica e o planejamento estratégico necessários para atos-limite, mas ele próprio fornecia sua própria forma de conhecimento crítico. Como Merleau-Ponty argumentou, subjacente ao sujeito pensante está uma consciência incorporada, então o homem trabalhador chega à consciência de classe apenas devido a sua existência anterior como classe trabalhadora:

Não é a economia ou a sociedade consideradas como sistema de forças impessoais que me qualificam como proletário, é a sociedade ou a economia tais como eu as trago em mim, tais como eu as vivo - e também não é uma operação intelectual sem motivo, é minha maneira de ser no mundo neste quadro institucional (Merleau-Ponty, 1962, p. 443) ${ }^{10}$.

Ou seja, uma vasta gama repleta de capacidades corporais inspira nossa existência e nosso saber. Conhecermos criticamente a nós mesmos e nossa situação é, primeiro e acima de tudo, motivado por uma

Educação \& Realidade, Porto Alegre, v. 38, n. 3, p. 831-851, jul./set. 2013.

Disponível em: <http://www.ufrgs.br/edu_realidade> 
Revisitando os Fundamentos da Educação para a Libertação

maneira corporal de engajamento com a vida diária, e qualquer conhecimento reflexivo cognitivo desta existência sempre vem depois deste conhecimento anterior e mais profundo do corpo.

Obviamente, o conhecimento corporal não é mais perfeito ou seguro do que o conhecimento sistemático construído através de investigações científicas ou outras formas eruditas, nem é necessariamente mais prontamente acessível ou adquirido. Também pode ser formatado por ideologias dominantes, psicologicamente reprimido ou simplesmente falseado. Algumas feministas e estudiosos descoloniais não apenas questionaram as formas de racionalidade anexadas ao projeto colonial que tentou exterminar ou silenciar conhecimentos indígenas e experiências das mulheres (Grosfoguel, 2007; Lugones, 2010; Sandoval, 2000), mas também examinaram as vulnerabilidades e o trabalho emocional que permite o aparecimento de conhecimento do corpo profundo (Boler, 1999; Collins, 2000; Moraga; Anzaldua, 2004). Freire reconhecia que a desumanização da opressão alcança a experiência psíquica da vida cotidiana e utilizou bastante os estudos de Frantz Fanon (1966; 1967) e Albert Memmi (1965) para esboçar a dinâmica psicológica resultante. Freire também fez gestos sugestivos rumo a métodos que poderiam se contrapor ao dano causado, mas não teorizou adequadamente sobre os recursos epistêmicos que também residem na psicologia do oprimido. Uma pedagogia verdadeiramente crítica deve acolher com maior totalidade a importância da intuição, dos sentimentos e das emoções por sua importância epistemológica e também por sua importância no alcance de um modo saudável de ser no mundo. Isto implica em metodologias que identifiquem, facilitem a expressão e examinem estas maneiras corporais de saber para que também possam ser articuladas à cura e à capacitação comunitária, que são componentes necessários do trabalho emancipatório (Beckett; Glass; Moreno, 2012).

Os insights da teoria feminista e descolonial reforçam a insistência de Freire de que a curiosidade e a busca/pesquisa incansável formam o âmago de nosso ser epistemológico e, assim, a educação como prática de liberdade deve continuar aberta à multiplicidade de conhecimentos e comprometida com uma avaliação continuada de todas as formas de saber. Uma consciência crítica incorporada não é estritamente a posse ou alcance de um indivíduo, nem pode ser testada fora dos atos-limite situados dentro de horizontes culturais e históricos específicos (ver Freire, 1994b, p. 100-105), de modo que estes processos colaborativos pragmáticos constituem os únicos controles possíveis de nosso saber.

A necessidade de uma contínua crítica e avaliação amplia-se para as identidades de pessoas oprimidas. A formulação binária universalista de opressor-oprimido de Freire em seu trabalho inicial com frequência supunha uma unidade de experiência de opressão que esquecia diferenças chave de raça, gênero e classe (Ellsworth, 1989; Weiler, 1991), embora os críticos reconhecessem que esta deficiência não minasse o valor de sua análise como um todo (McLaren; Leonard, 1994;

840 Educação \& Realidade, Porto Alegre, v. 38, n. 3, p. 831-851, jul./set. 2013. Disponível em: <http://www.ufrgs.br/edu_realidade> 
Weiler, 1994; 1996). Estas diferenças são vitalmente importantes tanto para a teoria como a prática de uma pedagogia crítica, particularmente porque a historicidade da opressão significa que raça, classe, gênero e outras opressões continuamente se adaptam e se intensificam em condições concretas específicas, constantemente passando por revisões contestadas que formatam tanto a identidade de fora quanto de dentro (Glass, 2000). Ademais, a dialética opressor-oprimido pode ser vivida de maneiras contraditórias, com pessoas individuais ocupando posições simultâneas de dominação e subordinação (por exemplo: um homem da classe trabalhadora é oprimido em relação a sua posição de classe, porém é privilegiado devido ao seu gênero; ou uma mulher branca de classe média é oprimida na ordem do gênero, mas é privilegiada por sua posição racial e de classe). Além disso, as afirmativas de conhecimento sobre identidade, mesmo dentro de críticas políticas aparentemente progressistas a respeito de raça e racismo, inevitavelmente incluem alguns traços ideológicos historicamente opressores (Glass, 2012). Como a identidade não possui nenhuma relação direta ou necessária com contextos externos ou representações internas (Taylor, 1989), todas as assertivas de uma posição autêntica de sujeito tornam-se ontológica e epistemologicamente suspeitas, mesmo que, todavia, exerçam força ética e política.

Estas complexidades onipresentes sobre identidade acarretam que projetos educacionais e lutas por libertação verdadeiramente emancipatórios devem não apenas contestar os limites institucionais e estruturais mantidos em vigência por coerção ideológica e força bruta e econômica, mas também almejar internamente enfrentar os impactos psíquicos negativos da opressão, bem como abrir canais claros para a expressão positiva do saber profundo que somente nossos corpos podem fornecer. A teoria de Freire, apesar de apontar para as exigências psicanalíticas da conscientização (Freire, 1994a; 1994b; Freire; Faundez, 1992), falha em situá-las em relação ao fundamento epistêmico da teoria e da identidade do oprimido. A complexidade e a intimidade, tanto da opressão como da libertação, precisam de mais atenção do que a teoria de Freire oferece. Além disso, este nexo de problemas levanta perguntas difíceis acerca da natureza da dominação e a psicologia dos grupos opressores que também se sustentam na educação como prática de liberdade. A hegemonia domina através de uma combinação complexa e em constante evolução de coerção e consentimento, e tanto as ideologias hegemônicas como as contra-hegemônicas envolvem múltiplas tensões e contradições (Gramsci, 1971). Freire captou isso e mapeou algumas destas forças em ação na consciência do oprimido, mas é necessária uma substantiva evolução para ter uma direção teórica clara para abordar pedagogicamente esta plêiade de problemas.

Felizmente, as comunidades indígenas que sobreviveram a sua confrontação com o colonialismo, a lógica universalista, o cientificismo e o restante do aparelho ideológico de subjugação e opressão oferecem alguma orientação. Os métodos de descolonização nos devolvem não

Educação \& Realidade, Porto Alegre, v. 38, n. 3, p. 831-851, jul./set. 2013.

Disponível em: <http://www.ufrgs.br/edu_realidade> 
Revisitando os Fundamentos da Educação para a Libertação

apenas nossos $e u$ incorporados, mas nossos $e u$ como coexistentes com outros seres e os recursos naturais do planeta que sustenta a todos nós; este retorno não é um movimento para trás na direção de um passado romantizado, mas sim uma maneira de avançar que começa com a humildade e o reconhecimento de verdades que precedem a linguagem (Smith, 2012). Quando falamos dos fundamentos de nossas vidasem-relação incorporadas, as verdades profundas de nossa situação são reveladas; quando falamos e anunciamos um mundo mais justo, ao mesmo tempo respondemos à opressão e denunciamos sua desumanização. Como Freire compreendeu, "Não há palavra verdadeira que não seja práxis. Daí que dizer a palavra verdadeira seja transformar o mundo" (Freire, 1994a, p. 68) ${ }^{11}$. Estudiosos indígenas enfatizam que é fundamental haver uma compreensão espiritual para este tipo de manifestação e das histórias que codificam o conhecimento crítico da comunidade (Vizenor, 1999). Estas narrativas emancipatórias provêm das intuições e sentimentos que nossos corpos usavam para prever o que aprendemos a dizer, e eles entrelaçam os insights adquiridos a partir de muitas fontes de saber.

Uma ontologia e epistemologia, historicizadas e incorporadas, oferecem embasamento teórico para a educação como prática de liberdade, mas, para ser completa, a teoria deve também elaborar a ética que precede este embasamento e que permite que esteja em coesão como uma base capaz de sustentar uma política consistente. Como nosso ser livre habita os espaços abertos por nossa historicidade e não consegue ser garantido por autenticidade, e como nosso saber não pode ser justificado com certeza, nossa ética deve ser vivida sem retidão, e nossas lutas por justiça devem ser retribuídas com não-violência militante (Glass, 2011). Freire (1994a; 1998a) nomeou determinados aspectos éticos (respeito, não discriminação, humildade, tolerância, amor e etc.) como importantes para sua teoria pedagógica, assim como nomeou o socialismo democrático como a finalidade de sua política, mas nem sua ética nem sua política jamais receberam uma base teórica sólida. No restante deste ensaio, eu amplio a visão de Freire e esboço uma teoria que forma uma estrutura consistente e integrada para uma ontologia, epistemologia, ética e política historicizadas ${ }^{12}$.

\section{Uma Ética e uma Política para a Educação como Prática de Liberdade}

A teoria da pedagogia crítica parece defender que quando pessoas boas, pelo menos aquelas que estão entre os oprimidos, compreendem a opressão e conhecem suas capacidades para transformarem a si mesmas e ao seu mundo, farão alguma coisa para mudar as condições opressivas da vida cotidiana. Se os oprimidos, conhecendo a verdade a respeito de sua situação, não agirem em seus interesses emancipatórios, então é geralmente presumido que estão sob influência do fatalismo, medo, alguma outra distorção ideológica ou consciência falsa. Estas 
suposições são similares àquelas das crenças morais do senso comum: pessoas boas, moldadas por sensibilidades éticas, com certeza saberão e farão a coisa certa. Porém, tanto considerações teóricas como uma perspectiva crítica sobre a experiência cotidiana colocam esta visão em xeque. As pessoas realmente determinam a coisa certa a fazer em determinada situação e com frequência agem de acordo com esta avaliação. Entretanto, raramente consideram a possibilidade e a importância de perspectivas éticas alternativas sólidas que poderiam desafiar estas avaliações. E mais frequentemente do que a maioria de nós admite, de fato não seguimos os ditames de nossa própria consciência ou julgamento, e isto é verdade mesmo para pessoas virtuosas de bom caráter.

Dificuldades adicionais emergem a partir de um pressuposto de que aqueles que lutam por justiça e democracia personificam o bem, e seus nobres objetivos não conseguem ser incorporados a seus próprios problemas éticos (Glass, 2002; 2004a). De fato, as transgressões necessárias das ordens sociais e políticas (injustas) estabelecidas que são realizadas em atos-limite emancipatórios são, em parte, ética e politicamente justificados por apelos a valores ou princípios mais elevados que parecem tornar as violações um dever. Mas e se estruturas éticas em disputa puderem desafiar estes valores e princípios, e se os defensores da justiça que lutam nas linhas de frente por justiça também possuírem pés de barro e intenções impuras? Estas ambiguidades e contradições éticas estão presentes não apenas no lado dos oprimidos, mas também habitam os mundos éticos dos opressores. Os assustadores dilemas éticos de lutas por justiça, a miríade de racionalizações por inconsistências éticas, o terreno desordenado da teoria ética e a carregada psicologia moral da vida cotidiana constroem nós duradouros que unem a ética e a política da educação como prática de liberdade.

Desde a antiguidade até o presente, líderes religiosos, juízes e pessoas comuns tentaram encontrar uma maneira eticamente satisfatória de ordenar o drama humano da história. Foram concebidos mandamentos sagrados, códigos legais e teorias filosóficas para orientar e advertir, para contrabalançar consequências e princípios, para justificar julgamentos com procedimentos de decisão sensatos e lógicos ou simplesmente para estabelecer o limite do que pode ser tolerado. Cânones de histórias e parábolas foram criados para instrução dos jovens, e a formação de virtudes e os sentimentos foram cultivados para manter a compreensão moral. No entanto, o domínio ético permanece sem regras, e cada caráter humano mantém seus defeitos particulares e, neste contexto, escolhas devem ser feitas para assumir um lado ou outro nas lutas por libertação. Seria necessário haver algum meio de resolver quais deveriam ser nossos compromissos éticos e políticos, mesmo em situações altamente complexas e contraditórias em que interagem múltiplas forças e estruturas éticas.

Se aceitarmos que a diversidade de perspectivas éticas e múltiplas maneiras de viver uma boa vida é uma parte primordial da condição 
Revisitando os Fundamentos da Educação para a Libertação

humana, da mesma forma que a diversidade de línguas naturais existe e desafia traduções singulares entre elas (Hampshire, 1983), então desistimos da tentativa de teorizar uma solução universal para nossos dilemas éticos e buscamos posições mais modestas. Conforme discutiu Primo Levi, sobrevivente de Auschwitz, mesmo no meio de horrores inenarráveis, a vida moral é representada em uma eterna zona cinzenta e não em tons de branco e negro (Levi, 1989). A zona cinzenta pode parecer solapar a própria possibilidade da ética, mas, para ser claro, males como assassinato e opressão não são eticamente ambíguos e deveriam ser condenados e enfrentados da forma mais forte possível. Nem a zona cinzenta significa que opressores e vítimas existam no mesmo nível moral ou compartilhem a culpa pela desumanização. Ao contrário, a zona cinzenta é onde indivíduos, coletividades sociais e comunidades habitam sua moralidade ao longo do tempo. Considere que o estado nazista e seus lacaios também demonstraram qualidades admiráveis de caráter e retidão, como lealdade, coragem, cooperação, dedicação a tarefas bem feitas e amor à família. E recorde que a devastadora angústia de Primo Levi emergiu do abismo existencial aberto pelas falhas éticas daquelas vítimas com caráter exemplar, mais do que devido à malevolência que o circundava. Suas fraquezas comuns (Shklar, 1984), tanto quanto sua cumplicidade com a normalização de atrocidades, questionam a própria bondade em si.

Nossa cumplicidade diária com danos em grande escala e nosso consentimento passivo com ideologias hegemônicas, sem mencionar nossas próprias falhas éticas menores, barram a retidão. Estes danos e ideologias destroem as chances na vida das pessoas, se não sua vida física imediata, e poderiam ser mitigados ou evitados com diferentes estruturas e relações institucionais e sociais. Milhões de pessoas, inclusive crianças, sofrem desnecessariamente pela pobreza, fome e desnutrição, saúde e atendimento odontológico inadequado ou inexistente e toxinas ambientais nos ambientes e residências onde vivem. Racismo, sexismo, classismo e outras ideologias dominantes prejudicam o bemestar psicológico e material de milhões. As próprias escolas, apesar das melhores intenções dos professores, também perpetuam estes mesmos danos através de seus mecanismos de classificação e seleção, transformando incontáveis crianças inocentes em ninguéns marginalizados, normalizando o sofrimento e as desigualdades da ordem escolar e produzindo a estrutura de opressão como desfecho de escolhas individuais face às oportunidades justas de sucesso (Glass, 2000).

Nosso compromisso com a luta por justiça não pode nos desconectar completamente destes sistemas e da vida na zona cinzenta, onde o senso comum trata vastos danos simplesmente como o jeito que as coisas são ou devem ser. O mito da retidão pessoal pode salvar consciências, mas reforça as barreiras psicológicas contra assumir total responsabilidade por manter sistemas opressivos e as maneiras como nos habitam, apesar de nossa rejeição consciente a elas. Viver com integridade na zona cinzenta também exige uma compreensão do modo como

844 Educação \& Realidade, Porto Alegre, v. 38, n. 3, p. 831-851, jul./set. 2013 Disponível em: <http://www.ufrgs.br/edu_realidade> 
a sorte formata nossas possibilidades de viver eticamente (Katz, 2009; Williams, 1981). Ainda mais, nossas escolhas aparentemente conscientes, mesmo pelo bem e do lado da luta pela justiça, podem ser mais verdadeiramente compreendidas como desfechos de motivações e autodecepções mais profundas, menos virtuosas e inconscientes. Poderosos e misteriosos desejos sexuais e instintos de sobrevivência novamente trazem à luz as maneiras como nossa consciência incorporada possui, subjacente a ela, motivações ocultas da avaliação consciente e quase impossíveis de perceber. Nossas avaliações e nossas ações possuem múltiplas camadas de significância ética emanando dos aspectos mais íntimos de nossa psicologia, bem como dos contextos históricos, culturais e ideológicos públicos de nossas vidas. A esperança só vem com o engajamento da luta interna e externa (Glass, 2013), e, como Freire compreendeu claramente, a honestidade frente à verdade ética exige que abandonemos a retidão e abracemos a humildade.

Que políticas são possíveis dadas as dimensões ontológicas, epistemológicas e éticas de existência que foram apresentadas nesta análise? O que pode significar ser um cidadão crítico, um defensor da justiça engajado nas turbulentas batalhas contra a opressão? Maquiavel há muito tempo atrás argumentou que a política do poder era amoral, que neste domínio somente importavam cálculos instrumentais e desfechos materiais. Mas Freire (1994a; 1998) e eu rejeitamos esta noção de política e insistimos que a qualidade ética das lutas por justiça é uma fonte chave de nossa resistência política. Não basta ter objetivos éticos nem ser mais virtuoso do que não ser. Desafiar poderes dominantes - os grupos que desfrutam de privilégios de raça, classe e gênero - implica em organizar, mobilizar e fazer valer a força material em favor de maneiras particulares de vida, compromissos éticos e políticos particulares que critiquem as desigualdades e defendam justiça e democracia claramente e sem ambiguidade.

Mesmo em um contexto social e político determinado por promessas formais de democracia e justiça, múltiplas afirmativas epistêmicas e éticas insolúveis e divergentes asseguram que o conflito será endêmico para a esfera pública e o discurso institucional e político. Alguns veem estes conflitos como oportunidades para fortalecer a democracia e melhorar a vida moral da sociedade (Gutmann; Thompson, 1996), e embora isto possa de fato ser um desfecho, permanece o fato de que, em uma democracia agressiva, o que conta no momento de decisão é a força ou o poder (Mouffe, 2005). Os profundos rasgos no tecido social, produzidos por injustiça e ideologias dominantes, e a implacável desumanização que recai sobre pessoas oprimidas, tanto ética como politicamente, justifica sua mobilização para impor seus interesses autodeterminados, e isso inclui sua desobediência e resistência às ordens social e legal que as oprimem (Walzer, 1970). Os defensores da justiça com frequência devem se comportar mal para derrubar as normas e instituições que os mantêm subservientes, e reconhecidamente estes atoslimite, que rompem o status quo e desafiam estruturas e ideologias in-

Educação \& Realidade, Porto Alegre, v. 38, n. 3, p. 831-851, jul./set. 2013.

Disponível em: <http://www.ufrgs.br/edu_realidade> 
Revisitando os Fundamentos da Educação para a Libertação

justas, também acarretam algum dano, embora mínimo, a alguns dos que resistem ao movimento de avanço da justiça. Conforme proclamou Frederick Douglass (1857):

Toda a história do progresso da liberdade humana mostra que todas as concessões já feitas as suas magnas demandas nasceram de lutas sérias. [...] Não há progresso sem luta. Aqueles que professam ser a favor da liberdade mas desaprovam a agitação são homens que querem colheita sem lavrar o solo; querem chuva sem relâmpagos nem trovões. Querem o oceano sem o terrível rugir de suas muitas águas. Esta luta pode ser moral ou pode ser física, podendo tanto ser moral como física, mas deve ser uma luta. A força não concede nada sem uma reivindicação. Nunca o fez e nunca o fará.

Estas lutas necessárias, sejam elas silenciosas ou rumorosas, e os danos, pequenos ou grandes, ressaltam para todos os lados a importância da base ética da política. As relações com os outros, tanto aliados como oponentes, tanto oprimidos como opressores, estão no âmago de nossa humanidade e invadem toda nossa historicidade. Embora nossas relações com opressores estendam nossa ética e política quase até seus pontos de ruptura, uma práxis verdadeiramente emancipatória deve se opor a todos aqueles que estão cheios de certeza de retidão e se sentem ligados apenas aos seus e, assim, são livres na busca de seus objetivos. Nosso inacabado estar no mundo, nosso conhecimento incerto e nossa moralidade sem retidão encontram sua realização em uma forma de luta política que aposta seu poder sobre a não-violência militante. Mahatma Gandhi e Martin Luther King Jr., forneceram lições vivas na teoria e na prática desta forma de luta (Ansbro, 2000; King, 1991), e outros refinaram suas estratégias e táticas para revelar como a ação vigorosa comprometida pode continuar consistente com obrigações éticas e epistêmicas e rivalizar com o poder dos exércitos (Sharp, 1970, 1990). A história mundial fala deste poder; “[...] o arco do universo moral é longo, mas se curva em direção à justiça”" (King, 1991).

\section{Considerações Finais}

Conforme tentei demonstrar neste ensaio, uma teoria sobre os fundamentos da educação para libertação completamente desenvolvida revela um modo poderoso de luta por justiça que continua consistente com nosso ser ontológico, nossas capacidades epistemológicas, nossas possibilidades éticas e nossas necessidades políticas. Aqueles que são verdadeiros defensores da justiça não procuram heroísmo nem martírio, mas sim se preparam para um modo de vida que empurre os limites de cada situação para uma visão de equidade e democracia; isto é tanto uma estratégia de transformação mais humilde como de maior alcance. Seus desafios determinados a poderes arraigados, ideologias desumanizadoras e exploração econômica são implacáveis e são for-

846 Educação \& Realidade, Porto Alegre, v. 38, n. 3, p. 831-851, jul./set. 2013 Disponível em: <http://www.ufrgs.br/edu_realidade> 
jados nas comunidades de solidariedade e amor. A consciência crítica, transformadora e diferencial (Sandoval, 2000), que emerge da educação como uma prática de liberdade, permite que incorporemos nossas verdades mais profundas, nossa ética mais substancial e nossa política mais comprometida. Paulo Freire viveu sua vida no espaço desta consciência; é por isso que inspirou e energizou pessoas no mundo inteiro, e é por isso que seu legado se prolongará muito além de qualquer horizonte que possamos enxergar agora. Freire sempre estava buscando se tornar mais humano, tornar possível que outros fossem mais humanos e, se acolhermos esta busca com tanto amor e determinação quanto ele, então uma maior medida de justiça e democracia estará ao alcance.

Recebido em 15 de março de 2013 Aprovado em 12 de junho de 2013

\section{Notas}

1 On Paulo Freire's philosophy of praxis and the foundations of liberation education. Educational Researcher, Sage Publications, v. 30, n. 2, p. 15-25, 2001.

2 Conforme W. V. O. Quine discutiu em Philosophy of Logic (1970, p. 35): “A lógica persegue a verdade ao subir a árvore da gramática”. Eu diria que essa verdade é incorporada e não pode ser capturada pela lógica nem contida pela linguagem, continuando sempre além do alcance de ambas.

3 Nota da Tradução (N. T.): FREIRE, Paulo. À Sombra desta Mangueira. São Paulo: Olho D'água, 1995, p. 18.

4 N. T.: Freire, 1995, p. 18.

5 N. T.: Freire, 1995, p. 18

6 N. T.: FREIRE, Paulo. Por uma Pedagogia da Pergunta. Rio de Janeiro: Paz e Terra, 1985, p. 21.

7 N. T.: Freire, 1995, p. 75-76.

8 A partir de conversas pessoais que tive com Freire em 1984, sei que seu pensamento foi profundamente inspirado pela Fenomenologia da Percepção de Merleau-Ponty, embora Freire formalmente não citasse com frequência esta influência sobre sua abordagem à compreensão de uma consciência incorporada. Para uma reflexão sobre um pouco do meu trabalho com Freire em 1984, ver meu capítulo em Wilson; Park; Colón-Muñiz, Memories of Paulo (2010).

9 Sou grato a Bettina Aptheker por este exemplo em particular.

10 N. T.: MERLEAU-PONTY, Maurice. Fenomenologia da Percepção. Tradução de Carlos Alberto Ribeiro de Moura. São Paulo: Martins Fontes, 1999, p. 594.

11 N. de T.: Freire, 1985, p. 91.

12 Meus comentários limitados sobre ética e política em Educational Researcher (2001) foram substantivamente desenvolvidos no meu ensaio de 2011, Critical Pedagogy and Moral Education, e a posição seguinte decorre fortemente dessa discussão. 
Revisitando os Fundamentos da Educação para a Libertação

\section{Referências}

ANSBRO, John. Martin Luther King Jr.: nonviolent strategies and tactics for social change. Lanham, MD: Madison Books, 2000.

APPLE, Michael. Can Education Change Society? New York: Routledge, 2013.

BECKETT, Linnea; GLASS, Ronald David; MORENO, Ana Paulina. A Pedagogy of Community Building: re-imagining parent involvement and community organizing in popular education efforts. Journal of the Association of Mexican American Educators, Phoenix, Arizona State University, v. 6, n. 2, p. 5-14, 2012.

BHATTARCHARYA, Asoke. Paulo Freire: Rousseau of the $20^{\text {th }}$ century. Rotterdam, Netherlands: Sense Publishers, 2011.

BOLER, Megan. Feeling Power: emotions and education. New York: Routledge, 1999.

BOWERS, Chet. Linguistic Roots of Cultural Invasion in Paulo Freire's pedagogy. Teachers College Record, New York, Columbia University, v. 84, n. 4, p. 935953, 1983.

BOWERS, Chet; APFFEL-MARGLIN, Frèdèrique. Rethinking Freire: globalization and the environmental crisis. Mahwah: Lawrence Erlbaum, 2005.

BROWN, Cynthia. Literacy in $\mathbf{3 0}$ Hours: Paulo Freire's process in Northeast Brazil. Chicago: Alternative Schools Network \& Center for Open Learning and Teaching, Inc, 1978.

COLLINS, Patricia Hill. Black Feminist Thought: knowledge, consciousness and the politics of empowerment. New York: Routledge, 2000.

DARDER, Antonia. Reinventing Paulo Freire: a pedagogy of love. Boulder: Westview Press, 2002.

DOUGLASS, Frederick. Two Speeches by Frederick Douglass (1857). Rochester, NY, 1857. Disponível em: <http://www.blackpast.org/?q=1857-frederick-douglass-if-there-no-struggle-there-no-progress>. Acesso em: 25 jun. 2013.

ELLSWORTH, Elizabeth. Why doesn't this feel Empowering? Working through the repressive myths of critical pedagogy. Harvard Educational Review, Cambridge, MA, v. 59, n. 3, p. 297-324, 1989.

FANON, Frantz. The Wretched of the Earth. New York: Grove Press, 1966.

FANON, Frantz. Black Skin, White Masks. New York: Grove Press, 1967.

FISCHMAN, Gustavo; MCLAREN, Peter. Rethinking Critical Pedagogy and the Gramscian and Freirean Legacies: from organic to committed intellectuals, or, critical pedagogy, commitment, and praxis. Cultural Studies - Critical Methodologies, Thousand Oaks, Sage Publications, v. 5, n. 4, p. 425-447, 2005.

FISCHMAN, Gustavo et al. (Org.). Critical Theories, Radical Pedagogies, and Global Conflicts. Lanham: Rowman \& Littlefield Publishers, 2005.

FOUCAULT, Michel. The Archeology of Knowledge, and, The Discourse on Language. New York: Pantheon, 1972.

FOUCAULT, Michel. The Order of Things: an archeology of the human sciences. New York: Vintage, 1973.

FREIRE, Paulo. Por uma Pedagogia da Pergunta. Rio de Janeiro: Paz e Terra, 1985.

FREIRE, Paulo. À Sombra desta Mangueira. São Paulo: Olho D’água, 1995.

FREIRE, Ana Maria Araújo. Chronicles of Love: my life with Paulo Freire. New York: Peter Lang, 2001.

848 Educação \& Realidade, Porto Alegre, v. 38, n. 3, p. 831-851, jul./set. 2013

Disponível em: <http://www.ufrgs.br/edu_realidade> 
FREIRE, Paulo. Pedagogy of the Oppressed. $20^{\text {th }}$ Anniversary Edition. New York: Continuum, 1994a.

FREIRE, Paulo. Pedagogy of Hope. New York: Continuum, 1994b.

FREIRE, Paulo. Pedagogy of the Heart. New York: Continuum, 1997/2004.

FREIRE, Paulo. Pedagogy of Freedom: ethics, democracy, and civic courage. Lanham: Rowman \& Littlefield Publishers, 1998a.

FREIRE, Paulo. Teachers as Cultural Workers: Letters to those who dare teach. Boulder: Westview Press, 1998b.

FREIRE, Paulo. Pedagogy of Indignation. Boulder: Paradigm Publishers, 2004.

FREIRE, Paulo; FAUNDEZ, Antonio. Learning to Question. New York: Continuum, 1992.

GIROUX, Henry. On Critical Pedagogy. New York: Continuum, 2011.

GLASS, David. Education and the Ethics of Democratic Citizenship. Studies in Philosophy and Education, Ohio Valley Philosophy of Education Society, v. 19, n. 3, p. 275-296, 2000.

GLASS, David. On Paulo Freire's Philosophy of Praxis and the Foundations of Liberation Education. Educational Researcher, Sage Publications, v. 30, n. 2 p. $15-25,2001$.

GLASS, David. On Transgression, Moral Education, and Education as a Practice of Freedom. In: RICE, Suzanne (Org.). Philosophy of Education. Urbana, IL: Philosophy of Education Society, 2002. P. 120-128.

GLASS, David. Pluralism, Justice, Democracy and Education: Conflict and citizenship. In: ALSTON, K. (Org.). Philosophy of Education. Urbana, IL: Philosophy of Education Society. P. 158-166.

GLASS, David. Critical Pedagogy and Moral Education. In: DEVITIS, John; YU, T. (Org.). New Directions in Character and Moral Education. New York: Peter Lang Publishers, 2001. P. 227-239.

GLASS, David. Entendendo Raça e Racismo: por uma educação racialmente crítica e antiracismo. Revista Brasileira de Estudos Pedagógicos, Brasília, v. 93, n. 235 p. 885-913, 2012.

GLASS, David. The Critical Hope of Liberation Struggles: the antidote to despair in antiracism education. In: BOZALEK, Vivienne et al (Org.). Discerning Critical Hope in Educational Practices. V. Oxford: Routledge. In press, 2013.

GRAMSCI, Antonio. Selections from the Prison Notebooks. New York: International Publishers, 1971.

GREENE, Maxine. In Search of a Critical Pedagogy. Harvard Educational Review, Cambridge, MA, v. 56, n. 4, p. 427-441, 1986.

GREENE, Mazine. The Dialectic of Freedom. New York: Teachers College Press, 1988.

GROSFOGUEL, Ramón. The Epistemic Decolonial Turn. Cultural Studies, v. 21, n. 2-3, p. 211-223, 2007.

GUTMANN, Amy; THOMPSON, Dennis. Democracy and Disagreement. Cambridge, MA: Belknap Press, 1996.

HAMPSHIRE, Stuart. Morality and Conflict. Cambridge, MA: Harvard University Press, 1983.

KATZ, Michael. Teaching with Integrity. In: GLASS, Ronald David (Org.). Philosophy of Education. Urbana, IL: Philosophy of Education Society, 2009. P. 1-11. 
Revisitando os Fundamentos da Educação para a Libertação

KING, Martin Luther Jr. Letter from Birmingham City Jail. In: CARSON, Clayborn et al. (Org.). The Eyes on the Prize Civil Rights Reader: documents, speeches, and firsthand accounts from the Black Freedom Struggle, 1954-1990. New York: Penguin Books, 1991. P. 153-158.

KIRKENDALL, Andrew J. Paulo Freire and the Cold War Politics of Literacy. Chapel Hill: University of North Carolina Press, 2010.

KIRYLO, James D. Paulo Freire: the man from Recife. New York: Peter Lang, 2011.

LEVI, Primo. The Gray Zone. In: LEVI, Primo. The Drowned and the Saved. New York: Vintage Books, 1989. P. 36-69.

LEWIS, Tyson. E. Aesthetics of Education: theater, curiosity, and politics in the work of Jacques Rancière and Paulo Freire. New York: Continuum, 2012.

LUKE, Carmen; GORE, Jeniffer (Org.). Feminisms and Critical Pedagogy. New York: Routledge, 1992.

LUGONES, Maria. Toward a Decolonial Feminism. Hypatia, New York, WileyBlackwell, v. 22, n. 1, p. 186-209, 2010.

MARGONIS, Frank. Leftist Pedagogy and Enlightenment Faith. In: THOMPSON, Audrey (Org.). Philosophy of Education: 1993. Urbana: Proceedings of the Philosophy of Education Society, 1994. P. 250-262.

MAYO, Peter. Gramsci, Freire, and Adult Education: possibilities for transformative action. New York: Zed Books, 1999

MAYO, Peter. Liberating Praxis: Paulo Freire's legacy for radical education and politics. Westport: Praeger Publishers, 2004

McLAREN, Peter. Che Guevara, Paulo Freire, and the Pedagogy of Revolution. Lanham, MD: Rowman \& Littlefield Publishers, 2000.

McLAREN, Peter; KINCHELOE, Joe (Org.). Critical Pedagogy: where are we now? New York: Peter Lang, 2007.

McLAREN, Peter; LEONARD, Peter (Org.). Paulo Freire: a critical encounter. London: Routledge, 1994.

MEMMI, Albert. The Colonizer and the Colonized. New York: Orion Press, 1965. MERLEAU-PONTY, Maurice. The Phenomenology of Perception. Tradução de C. Smith. London: Routledge \& Kegan Paul, 1962.

MERLEAU-PONTY, Maurice. Fenomenologia da Percepção. Tradução de Carlos Alberto Ribeiro de Moura. São Paulo: Martins Fontes, 1999.

MORAGA, Cherríe; ANZALDUA, Gloria (Org.). This Bridge Called my Back. Berkeley: Third Woman Press, 2002.

MOUFFE, Chantal. The Democratic Paradox. London: Verso, 2005.

O'SHEA, Andrew; O’BRIEN, Maeve (Org.). Pedagogy, Oppression, and Transformation in a 'Post-critical' Climate: the return to Freirean thinking. New York: Continuum, 2011.

PERRY, Patricia. A Composition of Consciousness: roads from Freire and Elbow. York, NY: Peter Lang, 2000.

RICHARDS, Michael; THOMAS, Pradip; NAIN, Zaharon (Org.). Communication and Development: the Freirean connection. Cresskill: Hampton Press, 2001.

ROBERTS, Peter. Education, Literacy, and Humanization: exploring the work of Paulo Freire. Westport: Bergin \& Garvey, 2000.

850 Educação \& Realidade, Porto Alegre, v. 38, n. 3, p. 831-851, jul./set. 2013 Disponível em: <http://www.ufrgs.br/edu_realidade> 
ROSSATTO, Cesar Augusto. Engaging Paulo Freire's Pedagogy of Possibility: from blind to transformative optimism. Lanham: Rowman \& Littlefield Publishers, 2005.

SANDOVAL, Chela. Methodology of the Oppressed. Minneapolis: University of Minnesota Press, 2000.

SCHUGURENSKY, Daniel. Paulo Freire. New York: Continuum, 2011.

SHARP, Gene. Exploring Nonviolent Alternatives. Boston: P. Sargent, 1970.

SHARP, Gene. Civilian-based Defense: a post-military weapons system. Princeton: Princeton University Press, 1900.

SHKLAR, Judith. Ordinary Vices. Cambridge: Belknap Press of Harvard University Press, 1984.

SLATER, Judith; FAIN, Stephen; ROSSATTO, Cesar (Org.). The Freirean Legacy: Educating for social justice. New York: Peter Lang, 2002.

SMITH, Linda Tuhiwai. Decolonizing Methodologies: research and indigenous peoples. 2. ed. London: Zed Books, 2012.

SOUTO-MANNING, Mariana. Freire, Teaching, and Learning: culture circles across contexts. New York: Peter Lang, 2010.

TAYLOR, Charles. Sources of the Self: the making of the modern identity. Cambridge: Harvard University Press, 1989.

TORRES, Carlos Alberto. Education and Neoliberal Globalization. New York: Routledge, 2009 .

VIZENOR, Gerald. Manifest Manners: narratives on postindian survivance. Lincoln: University of Nebraska Press, 1999.

WALCOTT, William. Knowledge, Competence, and Communication: Chomsky, Freire, and the communicative movement. Montreal: Black Rose, 2006.

WALZER, Michael. Obligations: essays on war, disobedience, and citizenship. Cambridge, MA: Harvard University Press, 1970.

WEILER, Kathleen. Freire and a Feminist Pedagogy of Difference. Harvard Educational Review, Cambridge, v. 61, n. 4, p. 449-474, 1991.

WEILER, Kathleen. Rereading Paulo Freire. In: WEILER, Kathleen (Org.) Feminist engagements: reading, resisting, and revisioning male theorists in education and cultural studies. New York: Routledge, 1994.

WEILER, Kathleen. Myths of Paulo Freire. Harvard Educational Review, Cambridge, v. 66, n. 2, p. 353-371, 1996.

WILLIAMS, Bernard. Moral Luck. Cambridge: Cambridge University Press, 1981.

Ronald David Glass é professor de Filosofia da Educação do Departamento de Educação da Divisão de Ciências Sociais da Universidade da Califórnia, Santa Cruz. É também diretor do University of California Center for Collaborative Research for an Equitable California (www.ccrec.ucsc.edu). Seu trabalho foca-se na educação como formação de sociedades igualitárias, pluralistas e democráticas.

E-mail: rglass@ucsc.edu

Tradução: Ananyr Porto Fajardo

Revisão Técnica da Tradução: Luís Armando Gandin

Educação \& Realidade, Porto Alegre, v. 38, n. 3, p. 831-851, jul./set. 2013.

Disponível em: <http://www.ufrgs.br/edu_realidade> 